\title{
Reliability Performance of Shipboard Power Complexes with Regard to Ecosystem Effects
}

\author{
Victoria Aleksandrovna Plotkina ${ }^{1 *}$ \\ ${ }^{1}$ Far Eastern State Technical Fisheries University, Engineering Disciplines Department, 52 B \\ Lugovaya Str., Vladivostok 690087, Russia
}

\begin{abstract}
The article deals with the impact of ecosystem on the operability of ship power systems. It is shown, that influence is caused by fouling of a vessel hull by various microorganisms, spontaneous destruction of external structures of vessels and hydrometeorological external factors. Methods of solving the problem of ecosystem impact on power complexes of marine equipment are given.
\end{abstract}

\section{Introduction}

The ecological system in all its variety is an integral part of the majority of factors determining optimum operation of an onboard complex of systems and units of a fishery vessel. The totality of ecosystem components forms reliability criteria and indicators, by which the performance of ship power complexes can be judged. Signs of adverse action, components of an ecosystem include: degree and intensity of a fouling of an underwater part of a vessel by bacteria, unicellular organisms, invertebrates and algae; electrochemical, biological and chemical corrosion of above-water and underwater parts of a vessel; condition of current weather at navigation and dangerous weather phenomena during vessel voyage.

Fouling of ships with various microorganisms (Figure 1) leads to changes in the seaworthiness of the ship, namely a decrease in buoyancy, runability, controllability and stability. As a result, the resistance of the water to vessel movement increases and consequently fuel consumption increases. At the same time, ship structures and components are exposed to aggressive environments in extremely unfavourable conditions which can cause damage and destruction. Hydrometeorological external factors due to risks and consequences of damage to ship structures may result in damage to shipboard equipment operation as a whole.

It is known that shipboard equipment is combined into power complexes, which transform primary energy of organic, in particular chemical fuel, into heat energy with subsequent transformation of this type of energy into mechanical and electric power. At that, mechanical energy is consumed for the purpose ensuring vessel's motion in water stream by means of propulsion, as well as for reproduction of on-board mechanical systems and devices operation. In turn, electrical energy is consumed by various auxiliary mechanisms. The reliability of auxiliary mechanisms, in particular the anchor and steering mechanisms,

* Corresponding author: vika_plotkina@mail.ru 
determines the ability of technical devices and units to perform their functions, ensure safe navigation, unsinkability of ships, as well as provide good hygienic and living conditions.

It follows from the above that power complexes are one of the main elements of any ship. As a result, their fail-safety and reliability form important indicators of functioning of marine technical object and providing of safety of crew members. Study of influence of above signs of performance of components of an ecosystem on serviceability of ship power complexes allows to provide safety of navigation of a vessel, and also to predict accompanying actions for the purpose of prevention of failure of devices and mechanisms of a vessel as a whole.

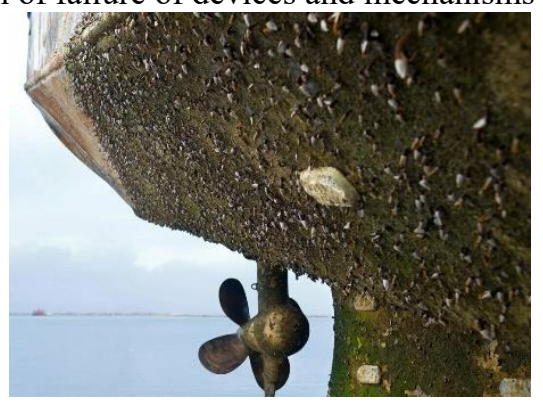

Fig. 1. Fouling of the bottom of the ship by micro-organisms

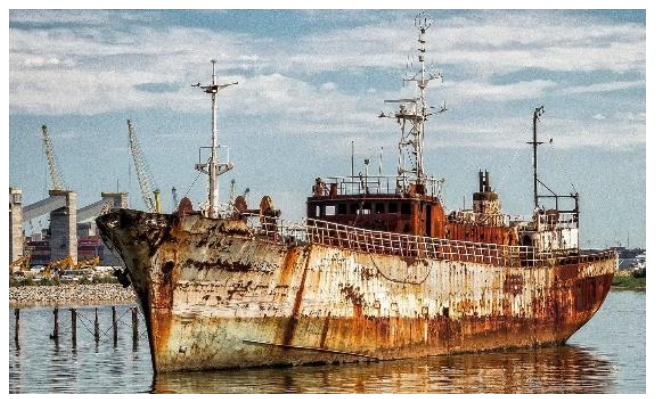

Fig. 2. Corrosion of vessel components

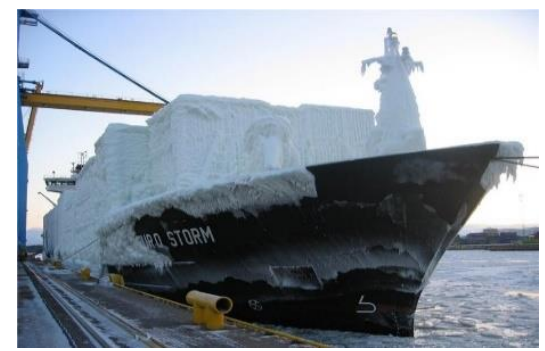

Fig. 3. Ship icing

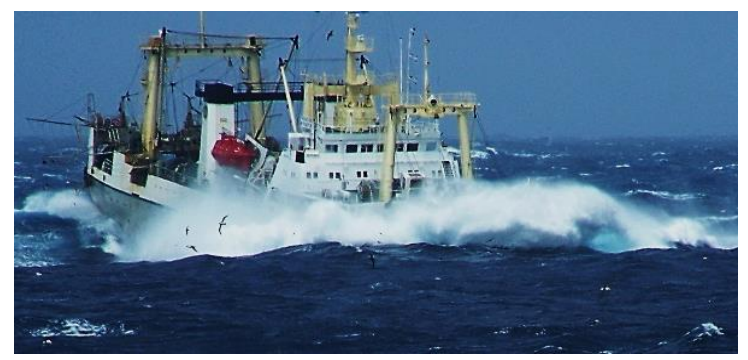

Fig. 4. Vessel sailing in stormy conditions 
Traditional practice of certification of serviceability, faultlessness and reliability of parts and units of ship power complexes has more prescriptive character and is limited to normative methods. Prescriptive methods are not flexible enough in qualitative research of reliability indicators of ship power complexes, including in view of ecosystem influence [1]. As a consequence it is necessary to consider in detail criteria on which it is expedient to designate more precisely factors which can essentially influence integrity, functionality and serviceability of power complexes of a vessel.

At present the most part of scientific works is devoted to studying of ecological problems at operation of ship power plants [2], dynamics of sea area pollution [3-6], researches of the reasons of bacterial population decrease [7-8] and many other scientific researches in the field of oceanography. At the same time the listed researches consider a problem of influence of marine objects at operation on ecological safety of environment which do not give the full answer to a question: how to provide safety of navigation at presence of inherent factors of influence of ecosystem on power complexes of a vessel? Therefore for the purpose of the fruitful answer to the set question in the given article some researches on revealing of indicators of reliability of ship power complexes taking into account influence of an ecosystem are resulted. Besides, urgency of research processes is confirmed by necessity to formulate criteria of an estimation of safety of the crew and a vessel itself in view of influence of a wide variety of adverse external conditions, including on the part of ecosystem, connected subsequently with expedient functioning of ship power complexes in view of arising risks [9-12].

A great variety of new technical solutions prescribes the necessity of optimal selection of performance reliability indicators ship power complexes. Therefore, in spite of abundance of researches in the field of assurance of reliability and safety of ship power plants taking into account influence, the problem of definition of reliability indicators remains actual.

\section{Materials and methods}

According to the classification of Russian Maritime Registry of Shipping, the main causes of emergency situations are: violations of the International Regulations for Preventing Collisions at Sea; rules of technical operation; deterioration of ship repair; significant age of their service life; exhausted resource of vessel machinery and equipment; failure of crew members to comply with the requirements of regulatory documents; insufficient knowledge of maneuvering characteristics and rules of navigation in complex navigational and hydrometeorological conditions [13]. Proceeding from the listed above it follows that it is necessary to consider in detail each aspect of origin of possible negative results of influence of adverse factors on structures, including a fishing vessel. The specified circumstance is possible to carry out by means of the detailed analysis of all possible reasons of origin of probable dangers during vessel operation, and also consideration of their interrelation and influence on working capacity of critical units of units and mechanisms of a vessel.

The issue of navigational safety determines the risks to the life of the ship's crew, which can be caused by various circumstances regardless of the climatic region of the voyage. In addition to the circumstances mentioned in the literature [14-17], these may include fouling of the hull by various micro-organisms, spontaneous failure of the outer hull shell and external factors associated with weather phenomena.

To ensure the integrity of structures and components of shipboard systems and aggregates, it is necessary to identify a number of criteria by which the operability and reliability of an installation can be assessed. This point of view make it possible to foresee at an early stage undesirable consequences related to failure of strength and rigidity of critical structures and structural elements of ship power complexes, as well as to ensure that necessary measures are taken at an early stage of detection. Thus it is known, that reliability 
of all systems of a vessel is one of safety guarantors. Besides, analysis of general properties on maintenance of safety of navigation in the presence of factors of influence of an ecosystem on power complexes of a vessel allows to define further algorithm of purposeful and systematic actions at stages of designing and operation of a vessel with the purpose of elimination of the phenomena connected with infringement of safety of navigation. Thus, using the conceptual approach on identification of indicators of reliability of ship power complexes taking into account influence of an ecosystem the brief review of accompanying provisions of safety of navigation promoting reduction of risks, accidents and undesirable incidents in the sea is considered.

As a result of definition of indicators of reliability of ship power complexes taking into account influence of ecosystem it is necessary to accent on an analytical method of knowledge of objective reality of influence of signs of productivity of action, components of ecosystem on maintenance of serviceability of the main element of a vessel. The choice of the given method of research is justified by necessity of systematization of tendencies of long-term results of research on prevention of accidents at sea. In view of the analysis of the specified direction of research it is possible to characterize the concept of reduction of influence of a degree of a fouling of a vessel hull by various micro-organisms, spontaneous destruction of external designs of vessels and hydrometeorological external factors on serviceability of an onboard complex of systems and units of a fishing vessel.

\section{Results and discussion}

Safety is an important objective of maritime development. Search and development of new approaches and methods to prevent ship accidents during their operation are becoming increasingly important [18]. Undoubtedly, promising methods to solve the problem of ecosystem impact on power complexes of marine equipment will allow predicting undesirable risks in the process of operation of any vessel.

Change of ship speed performance due to fouling by various micro-organisms are natural effects of the biogeocenosis on the exterior of ship structures. The microbial assemblage, however, varies from one voyage region to another, depending on the habitat.

The study of formation of fouling communities in their dynamics is the currentl task of many research centres. The main purpose of which is to develop installations for the study of fouling community formation patterns in different hydrodynamic flows and, as a result, to test and verify the properties of protective coatings on test substrates, including anti-fouling and anti-corrosion coatings [19-20]. Therefore, in order to reduce fouling by bacteria, unicellular organisms, invertebrates and algae, a variety of methods of protective coatings on ship hull now been proposed [21], nano-materials to prevent biofouling have been recommended [22], and various types of non-fouling coatings have been developed.

The main structures subject to attack by fouling microorganisms are ship hulls. Fouling of the hull is a continuous process, so the resistance to ship movement continuously increases as the fouling intensity increases. As the resistance to vessel movement increases, the heat load on the main engine of the vessel increases and subsequently the probability of damage and breakdown increases [23]. As a result, it is necessary to resort to estimation of degree of thermal loading on main diesel engines to increase service life of parts of cylinder-piston group. It is possible to carry out the assessment degree by means of construction of indicator diagrams showing cyclic temperature variations in the compression chamber wall of a diesel engine. By analysing these diagrams it is possible to realize the predicted results and assess the level of thermal stress on the diesel components.

In addition, the ship's cooling system is also affected by various types of fouling agents through the ship's hull. In view of the merits, a closed cooling system is recommended for use on ships. As a consequence, experimental studies are carried out to assess the effect of 
fouling on heat dissipation and appropriate designs of cladding heat exchangers are proposed [24].

A consequent factor of ecosystem impact on the operability of ship power systems is the spontaneous destruction of ship external structures due to corrosion (Figure 2). The course of general engineering sciences makes it possible to distinguish the types of corrosion damage depending on the type of corrosion processes, namely chemical, biological and electrochemical corrosion. As a result, it is revealed that all elements of ship power complexes are subject to corrosion. Corrosion causes significant damage to hull, pipelines, propeller and other ship structures. The cause of corrosion is complex application of sea water not only for cooling heat exchangers but also for generation of steam and fresh water from it. Thermal processing of ship-generated waste water can also cause corrosion. Fouling of the propulsion and steering complex and ship hull with biomass is another cause of corrosion.

Since seawater is highly corrosive medium, it is therefore important to take a set of protective measures to ensure corrosion resistance of ship's metal structures [25-26]. It should be noted that when a vessel is in port waters, corrosion processes develop more intensively than in relatively clean waters. Thus, to effectively combat corrosive effects, it is advisable to organize operational control of marine environment factors affecting the development of corrosive processes of destruction of vessel structural elements [27]. Despite a variety of protection methods - electrochemical protection (protector and cathodic), application of corrosion-resistant materials and corrosion inhibitors, paint-and-lacquer coating are the main method of strengthening corrosion resistance of ship power complex elements at present.

A seagoing vessel undergoes many hazards during its operational phase, including those from the environment [28]. Under the influence of hydrometeorological external factors adverse effects for ship power systems can occur. Wind effects, temperature and precipitation, visibility limitations due to fog are the expression of the impact on ship structural elements. Environmental effects on ships include icing (Figure 3), watering of fuel, structural failure due to the dynamic action of the water environment (Figure 4), storm sailing conditions (pitching and rolling), capsizing, loss of buoyancy and stability. In addition, humans, as crew members, can also be affected by the environment, both during the operational phase of the vessel and during emergencies.

Many scientific works [29-32] are devoted to basics of dynamic unsinkability of a vessel taking into account influence of hydrometeorological external factors. Researches in the area allow to find out under what circumstances possible emergence of extreme characteristics of ship power complexes on the verge of emergency situation at navigation and during navigation of a vessel, and also to estimate individual features of a vessel in conditions of concrete simulation of influence of existing hydrometeorological disturbances of various level and in characteristic combinations.

As a result of the above stated, we not that reliability of ship power complexes directly depends on properties of object to perform its function in the set limits taking into account the set conditions of its application including no-failure, maintainability and preservability. With the purpose of definition of quantitative characteristic of properties, single and complex reliability indicators are entered. Knowing dependence of reliability indicators on operation modes and operating conditions of onboard complex of vessel systems and units, it is reasonable to calculate reliability characteristics for all possible navigation conditions. Hence, it is possible to predict in advance and take measures providing high level of reliability and serviceability of parts and units of ship power complexes.

Thus, one of the qualitative indicators of reliability is the service life, which is determined by the operating time. The subsequent indicator of reliability can be noted the surface durability of structural elements taking into account the service life reserve. The maintainability of components and interchangeability of details of power complexes are an integral part of reliable operation system under operation and abnormal conditions of vessel 
sailing. In studying influence of ecosystem on serviceability of ship power complexes, particular reliability indices can be singled out. They are: operational safety; operation in special conditions, extent of failure-free operation forecast; number of failures; extent of repair works implementation; forecast of labour input of works spent on repair. In addition, a qualitative indicator of operational reliability is readiness to function, taking into account international and national regulations [33]. Economic efficiency, environmental safety and manufacturability are indispensable indicators of ship power plant reliability [34].

Revealing of an estimation of reliability of ship power complexes taking into account influence of an ecosystem is feasible by means of development of methodical and software. These methodologies will make it possible to diagnose change in the reliability of ship power complexes, taking into account the impact of ecosystem. So for example, N. E. Petrova offers a technique of an estimation of reliability of the vessel hull on output parameters of deterioration of its elements [35]. Thus, the regulations of techniques can be various.

A complex of measures on definition of reliability indicators of ship power complexes with regard of ecosystem influence includes selection of optimum design solutions, reservation, forecasting, diagnostics, annual operating costs, provision with spare parts and tools, serviceability control, adjustment of remaining service life during operation.

\section{Conclusions}

The present article shows that influence ecosystem on serviceability of ship power complexes is caused by fouling by various micro-organisms, spontaneous destruction of ship external structures and hydrometeorological external factors. Methods of decision of a problem of influence of an ecosystem on power complexes of sea engineering demand careful working out and detailed elaboration both at a design stage of a vessel, and at a stage of operation in any conditions of navigation. Assessment of reliability of ship power complexes will allow to prevent or foresee consequences of influence degree and intensity of fouling of a vessel underwater part by microorganisms, and also corrosion of above-water and underwater parts of a vessel, a condition of current weather at navigation and dangerous weather phenomena during vessel sailing.

The specific feature of a ship power plant is the presence of a large number of complex equipment with manifold functional connections. Therefore, definition of probability of nofailure operation of ship power complexes with regard to ecosystems influence is labourintensive process including a great variety of criteria and reliability indicators. Registration of revealed reliability indicators will provide lower costs for repair works connected with replacement of units or repair of auxiliary mechanisms, proper level of risk management, and also will increase economical operation of ship power complexes

\section{References}

1. H. Schoen. Managing the technical condition of ship structures in service on the basis of risk assessment. Journal of "Vestnik AZTU". Series: Marine Engineering and Technology, № 1, 71-77 (2013).

2. M. Gladkov, N. Gladkova. Ecological problems in operation of ship power plant. Journal of "Fundamental and Applied Research: Problems and Results", № 25, 65-73 (2016)

3. E. Kotel'yanets, K. Gurov, E. Tikhonova, S. Kondratyev. Pollutants in bottom sediments of Balaklava Bay (Black Sea). Marine Hydrophysical Journal, 35, № 5, 469-480 (2019)

4. S. Song, C. Zhao, W. An, X. Li, C. Wang. Analysis of impacting factors on polarimetric SAR oil spill detection. Journal of "Acta Oceanologica Sinica", 37, 77-87 (2018) 
5. B. Paka, V. Chechko. Bottom sediment survey near underwater pollution sources. Journal of Oceanology, 58, № 5, 803-808 (2018)

6. E. Chernova, S. Kozhenkova. Spatial assessment of metal pollution in Peter the Great Bay (Sea of Japan) by the brown alga Sargassum miyabei. Journal of Oceanology, 60, № 1, 49-56 (2020)

7. O. Rylkova, I. Polikarpov. Seasonal dynamics and spatial distribution of structural indicators of the bacterioplankton community of Sevastopol Bay (Crimea, Black Sea). Marine Biological Journal, 6, № 1, 82-101 (2021)

8. Z. Finenko, I. Mansurova, I. Kovaleva, E. Georgieva. Development of phytoplankton in winter-spring period in the coastal waters of Crimea. Marine Biological Journal, 6, № 1, 101-114 (2021)

9. D. Skorokhodov, L. Borisova, Z. Borisov. Principles and categories of maritime safety. Journal of "Vestnik MSTU. Proceedings of Murmansk State Technical University", 13, № 4/1, 719-729 (2010)

10. B. Dmitriev, V. Karetnikov. Methods of ensuring maritime safety in the implementation of unmanned technologies. Journal of "Admiral S.O. Makarov State Marine Engineering University Bulletin", № 6 (46), 1149-1158 (2017)

11. L. Borisova, D. Skorokhodov. Challenges for ensuring safety in the field of navigation. "RMRS Scientific and Technical Bulletin", № 35, 8-17 (2012).

12. A. Sobolenko, I. Turischev, M. Gomzyakov, O. Moskalenko. Failure analysis on fishing vessels in the Far East region. Journal of "Vestnik of ASPTU". Series: Marine Engineering and Technology, № 3, 48-55 (2019)

13. A. Mamakov, L. Pererva. Security of information radio communication at sea. Journal of "Information Society", № 2, 43-51 (2016)

14. B. Kurbenkov, A. Pourdenko. Analysis of maritime security problems: status and solutions. Journal of "Marine Intelligent Technologies", № 4-5 (42), 216-223, (2018)

15. O. Marandykina, D. Popov. Analysis of human error impact on navigation safety in modern conditions. Journal of "River Transport (XXI century)", № 4 (92), 46-48 (2019)

16. A. Marchenko, O. Borch, N. Andreassen, S. Kuznetsova, V. Ingimundarson, U. Jakobsen. Navigation safety and risk assessment challenges in the high north. INTERNATIONAL CONFERENCE ON MARINE NAVIGATION AND SAFETY OF SEA TRANSPORTATION: MARINE NAVIGATION, TRANSNAV 2017, 275-281 (Gdynia, 21-23 June 2017)

17. L. Wang, Q. Liu, S. Dong, C. Guedes Soares. Effectiveness assessment of ship navigation safety countermeasures using fuzzy cognitive maps. Journal of safety science, 117, 352-364 (2019)

18. V. Torskiy, V. Topalov, M. Chesnokova. Safety of navigation - conceptual foundation. Monograph of ACTIVITIES IN NAVIGATION: MARINE NAVIGATION AND SAFETY OF SEA TRANSPORTATION, 13-18 (2015)

19. A. Zvyagintsev. Sea fouling studies at the Institute of Marine Biology FEB RAS (1968-2006). Journal of "Vestnik FEB RAS", № 4, 3-16 (2007)

20. A. Zvyagintsev, S. Maslennikov, A. Tsvetnikov, A. Begun, N. Grigoryeva. A study on the formation of fouling communities in a regulated water flow unit. Marine Biological Journal, 6, № 1, 17-33 (2021)

21. M. Abacharaev, I. Abacharaev, M. Hasanov. Improvement of operational qualities of ships and their mechanisms by applying protective plasma coatings. Journal of "Vestnik of ASPTU". Series: Marine Engineering and Technology, № 1, 105-108 (2015)

22. Y. Ferreira-Vancato, F. Dantas, B. Fleury. Nanobiocides against marine biofouling. Journal of "Studies in natural products chemistry", 67, 463-514 (2021)

23. I. Woznicki. Damages and Failures of Diesel Engines. Examples and cause analysis. Technical literature, SPb: Morkniga Publishing House, 116 pp. (2006) 
24. K. Fedorovsky, N. Fedorovskaya. Effect of Fouling on Heat Dissipation through Ship's Cladding. Journal of "Vestnik VSUVT", 181-188 (2019)

25. O. Belov. Modern state of organization of complex protection of metal hulls of ships and vessels from corrosion. Journal of "Proceedings of R. E. Alekseev National State Technical University", № 3, 115-120 (2017)

26. Y. Matveev. Methods of ship hull protection against electrical corrosion. Proceedings of II International Scientific and Practical Conference "Mechanical Engineering: Innovative Aspects of Development", 191-193 (2019)

27. D. Shunkin, V. Shvetsov, O. Belavina, D. Archibisov. On the organization of in-situ studies of stray current fields on marine vessels. Journal of "Vestnik of Russian State Technical University". Series: Marine Engineering and Technology, № 2, 70-81 (2018)

28. B. Makarova, Y. Potekhin. On the role of hydrometeorological factors in creating emergency situations at sea. Journal of "Week of Science of St. Petersburg Marine Technical University", № 1(1), 40 (2018)

29. B. Dorozhko. Prevention of seagoing vessel overturning in conditions of wind-wave impact. Journal of "Safety and Emergency Problems", № 3, 51-60 (2012)

30. P. Schaub, S. Moskowkina. Dynamic assessment of emergency vessel rollover in storm conditions in the presence of roll. Maritime Gazette, № 1(65), 110-11 (2018)

31. O. Tretiakov, P. Shaub, S. Moskovka. Fundamentals of vessel dynamic unsinkability. Maritime Bulletin, № 2(74), 27-29 (2020)

32. O. Tretiakov, P. Shaub, S. Moskovka. Foundations of Ship Dynamical Unsinkability. Maritime Bulletin, № 3(75), 37-39 (2020)

33. A. Tyufanova. Composite states of readiness factor as a quantitative indicator of operational reliability of technical means of ship traffic control system. Journal of "Transportnoe Delo Rossii", № 4, 66-69 (2016)

34. I. Borovikova. Power systems of ship diesel power plants: justification of reliability requirements. Journal "Vestnik AZTU". Series: Marine Engineering and Technology, № 4, 40-48 (2017)

35. H. Petrova. Methodology for assessing the reliability of ship's hull. Journal of "Vestnik MSTU", 12, № 1, 42-45 (2009) 